\title{
A relação sujeito-objeto e a unidade afetivo-cognitiva: contribuições para a Psicologia e para a Educação
}

\author{
Cláudia Aparecida Valderramas Gomes \\ Universidade Estadual Paulista - SP
}

\begin{abstract}
Resumo
A relação entre problemas afetivo-emocionais e aprendizagem escolar se faz presente nas áreas da Psicologia e da Educação. Este estudo, de caráter teórico-bibliográfico, pesquisou elementos que confirmassem a tese da historicidade dos processos cognitivos e afetivos, dando a esses processos uma conotação social e simbólica, e por meio da Psicologia Histórico-Cultural abordou a relação entre sujeito e objeto e a unidade afetivo-cognitiva, propondo a superação do pensamento organicista e subjetivista. Sugeriu a importância de (re)pensar as relações que o sujeito estabelece com o entorno e o papel do conhecimento e das condições concretas de vida e de educação, e destacou a atividade como categoria fundamental na constituição das necessidades e motivos, bem como na formação de desejos e na objetivação desses, potencializando a aprendizagem e movendo o desenvolvimento, já que a formação da subjetividade em cada sujeito é efeito de um processo educativo que deve ser objeto de estudo tanto da Psicologia quanto da Educação.
\end{abstract}

Palavras-chave: Psicologia Histórico-Cultural, educação, afeto-cognição

\section{The subject-object relationship and the cognitive affective unit: contributions to Psychology and Education}

\begin{abstract}
The relationship between affective-emotional problems and school learning is present in areas of Psychology and Education. In the present study, of theoretical and bibliographic characteristics, we investigated elements that might confirm the thesis of the historicity of cognitive and affective processes, giving to these processes a social and symbolic connotation. Through the Historic-Cultural Psychology we approached the subjectobject relationship and affective-cognitive unit proposing to overcome the subjectivist and organicist thinking. The study suggested the importance for us to (re) think the relationships that the subject establishes with the environment, the role of knowledge and practical conditions of life and education. Besides, it highlighted the activity as a main category in the constitution of needs and motives, as well in the formation of desires and the objectification of them. In this way, it enhances the learning and promotes the development, considering that the formation of subjectivity in each subject is the effect of an educative process that shall be object of study of both Psychology and Education.
\end{abstract}

Keywords: Historic-cultural psychology, education, affection-cognition.

\section{La relación sujeto-objeto y la unidad afectivo-cognitiva: contribuiciones a la Psicología y la Educación}

\begin{abstract}
Resumen
La relación entre problemas afectivo-emocionales y aprendizaje escolar está presente en las áreas de Psicología y Educación. Este estudio, de carácter teórico-bibliográfico, investigó elementos que confirmaran la tesis de la historicidad de los procesos cognitivos y afectivos dándoles una connotación social y simbólica. Por medio de la Psicología Histórico-Cultural abordó la relación entre sujeto y objeto y la unidad afectivocognitiva, proponiendo superar el pensamiento organicista y subjetivista. Se sugiere la importancia de (re)pensar las relaciones que el sujeto establece con el entorno y el papel del conocimiento y de las condiciones concretas de vida e de educación. Se destaca, también, la actividad como categoría fundamental en la constitución de las necesidades y motivos, así como en la formación de deseos y en la objetivación de ellos, mejorando el aprendizaje y impulsando el desarrollo, ya que la formación de la subjetividad en cada sujeto es efecto de un proceso educativo que debe ser objeto de estudio tanto de la Psicología como de la Educación.
\end{abstract}

Palabras Clave: Psicología Histórico-Cultural, educación; afecto-cognición. 


\section{Introdução}

A relação entre problema afetivo-emocional e aprendizagem escolar tem suscitado a atenção de profissionais que desenvolvem seus trabalhos na interface com a Psicologia e a Educação (Collares \& Moysés, 1996; Meira, 2003; Patto, 1999, 2000; Souza, 1997, 2007). Segundo esses autores,é comum encontrarmos, entre educadores e psicólogos, concepções e práticas que tendem a relacionar aspectos emocionais e (não) aprendizado na escola.

Conforme Meira (2003, p. 49), até o fim da década de 1980 poucos autores que partem de uma perspectiva mais crítica dedicaram-se ao estudo dessa temática, o que possibilitou a emergência de trabalhos de base idealista "(...) que colocam equivocadamente as emoções como um campo isolado dos demais processos humanos." A ideia que ainda predomina na escola é a de que as emoções são prejudiciais, um impeditivo que por vezes atrapalha o processo de escolarização das crianças e jovens.

A partir dessa constatação buscamos, neste estudo, a sistematização de algumas teses a partir do aporte da Psicologia Histórico-Cultural, com a finalidade de desvelar os modos de constituição dos processos cognitivos e afetivos na atividade do sujeito, apontando suas implicações educacionais e colocando educadores e profissionais da Psicologia a pensar sobre alguns desdobramentos.

$\mathrm{O}$ primeiro deles refere-se à dicotomia afetivo e cognitivo, que, presente na escola, sustenta a ideia de que a prática pedagógica abarca tão somente o aspecto cognitivo, e assim não cabe a essa prática "trabalhar o afetivo" que, por vezes, impõe obstáculos à aprendizagem do sujeito, postura que acaba por eximir a educação escolar da sua responsabilidade pela formação da personalidade humana (Bissoli, 2005; Martins, 2006, 2007). O segundo diz respeito ao rompimento com a ideia das disposições intrínsecas do sujeito que aprende, propondo a superação de uma perspectiva naturalizante dos processos afetivos e recuperando o papel dos mediadores sociais (as relações interpessoais, os signos, os instrumentos, o conhecimento socialmente elaborado) como elementos transformadores dos afetos, com destaque para a educação escolar e o caráter intencional da prática docente nesse processo de desenvolvimento.

Partimos do pressuposto teórico e metodológico da Psicologia Histórico-Cultural, que, ao afirmar o caráter histórico e social da formação humana e a unidade afetivo-cognitiva no desenvolvimento da consciência, coloca a educação escolar como um espaço privilegiado na constituição de cada sujeito. Assim, colocamos a seguinte pergunta: é possível explicar a constituição e participação dos processos afetivos na atividade do sujeito deixando-se para a escola função de superar a dicotomia entre afeto e cognição, com vistas ao desenvolvimento integral da criança?

Trabalhamos com a hipótese de que é somente pela via da efetiva apropriação dos signos - fundamento do trabalho educativo - que se promovem formas mais desenvolvidas de pensamento e de que, dada a impossibilidade da dicotomia afeto e cognição na teoria da aprendizagem e desenvolvimento de L. S.Vigotski ${ }^{1}$ (1896-1934), estas conquistas intelectuais podem ser ativadoras de novos modos de pensar e sentir, passando a interferir diretamente na consciência e na atividade do sujeito. Essa proposição contraria a ideia, há muito estabelecida no espaço escolar, de que o trabalho com o afetivo pertence a outros profissionais que não os educadores, e nos coloca a pensar sobre o papel da educação escolar na apropriação dos signos e instrumentos - reais portadores da cultura humana - e sobre o que isso representa para o pleno desenvolvimento da criança. Daí o esforço em sistematizar as contribuições sobre a unidade afetivo-cognitiva apontadas pela Psicologia Histórico-Cultural que fizessem avançar os conhecimentos postos, até então, pela psicologia tradicional ${ }^{2}$, contribuindo para a construção de outra concepção de desenvolvimento humano e colocando ao educador a possibilidade de refletir sobre seu papel na educação das crianças.

Para tanto buscamos nas raízes filosóficas do pensamento vigotskiano sobre a constituição dos processos afetivos (Espinosa, século XVII, e Marx, século XIX) e nos autores da Escola de Vigotski argumentos sobre a unidade entre afeto e cognição que confirmassem a tese de que Vigotski buscou compreender esta unidade por intermédio dos signos e instrumentos, dando aos processos afetivos e cognitivos uma conotação social e simbólica.

\section{Cognição e afeto: primeiras aproximações}

Baruch de Espinosa ${ }^{3}$ (1632-1677) foi um dos representantes da nova atitude filosófica inaugurada no século XVII pelos racionalistas, gênese de outra compreensão quanto ao sujeito e quanto ao objeto do conhecimento. A ética de Espinosa assegura a entrada no período moderno da Filosofia e considera que as ideias que constituem a consciência advêm de uma realidade objetiva, portanto o pensamento pressupõe a existência da coisa; mas o que ela não explicitou é como essa coisa passa a ser parte da consciência do sujeito;ou, dito de outro modo, o que essa teoria não deu a conhecer foram os mecanismos da atividade humana como elemento constitutivo do conhecimento.

$\mathrm{Na}$ tentativa de reunir elementos explicativos sobre a constituição dos processos cognitivos e afetivos na atividade humana, entendemos necessária a referência a outro

1 Optamos, neste texto, pela grafia Vigotski para designação do nome desse autor, porém, no caso de citações e referências bibliográficas que possamos utilizar, respeitaremos as diferentes grafias adotadas nos textos originais.

2 Em seu texto O significado histórico da crise da psicologia (1991) Vigotski qualifica como tradicionais as vertentes idealistas e materialistas mecanicista da Psicologia.

3 Chauí (2005) adverte que o nome de Espinosa é grafado de maneiras diversas, aparecendo ora como "Espinoza", ora como "de Espinosa", "Spinosa", "Espinosa". Em suas obras, escritas em latim, o filósofo assinava "Benedictus de Spinoza". Respeitando a convenção atual, para a língua portuguesa adotamos, neste texto, a grafia "Espinosa". 
filósofo que superou as concepções até então consagradas à explicação da relação do sujeito com o objeto do conhecimento. Marcando a história da Filosofia a partir do século XIX, Marx (1818-1883) figura como a segunda influência na formação do pensamento vigotskiano, contribuindo significativamente para a compreensão da materialidade dos processos psicológicos humanos.

Se suas primeiras obras trazem muito mais a influência do materialismo e do racionalismo de Espinosa, é a partir das categorias legadas por Marx que o autor russo apresenta a tese de que a personalidade humana se forma com base nas relações sociais. As ideias de Marx sobre quem é o homem incluem a história e, sobretudo, a atividade que este homem realiza na história, elementos indispensáveis à superação do materialismo de Espinosa em direção a um materialismo que considera a atividade humana objetiva - práxis - na constituição da subjetividade do sujeito. Sem perder de vista o que cada um desses dois autores abordou no palco da Filosofia (Espinosa tratava da ética, e Marx, de uma teoria crítica da alienação humana no interior do sistema capitalista), elegemos aquelas contribuições que, circunscritas aos fundamentos das ideias vigotskianas, apontam para a unidade dos processos cognitivos e afetivos na relação do sujeito com o objeto do conhecimento. Falar desse lugar implica (re)visitar a relação entre sujeito e objeto nos processos de ensino e de aprendizagem que acontecem na escola, conformando a subjetividade das crianças.

A morte prematura de Vigotski interrompeu um novo ciclo de investigações que ele pretendia realizar sobre a natureza da consciência humana, que se dedicava à esfera motivacional, abarcando nossos desejos e necessidades, interesses e motivos, afetos e emoções. Conquanto possamos encontrar ao longo de sua obra (1972, 1987, 1991, 1993, 1995, 1996, 2000, 2003) fragmentos da sua concepção sobre a constituição dos processos afetivos na conformação da consciência humana, é num de seus últimos trabalhos - Teoría de las emociones. Estúdio histórico-psicológico (2004) escrito entre 1931-1933 -, que o autor pretendeu expor sua própria interpretação do problema.

Neste seu trabalho, que figura no sexto volume das Obras Escolhidas, Vigotski (2004) faz uma análise crítica da natureza da psicologia das emoções, indo à raiz dos seus pressupostos filosóficos e metodológicos e demonstrando, de forma detalhada, a complexa rede de relações que esta psicologia ainda mantém com os postulados cartesianos. $O$ núcleo dessa discussão consiste em que, por meio de uma análise criteriosa dos principais elementos do pensamento organicista de William James (1842-1910) e C.G.Lange (1834-1900), Vigotski vai desvelando o conteúdo ideológico dessa teoria e, ao final deste processo, contraria a principal tese defendida por esses dois autores: a de que a teoria de Espinosa seria o substrato filosófico da psicologia contemporânea das emoções.

Entre outros aspectos, neste trabalho Vigotski (2004) analisa criticamente os dois eixos fundamentais que marcam a premissa a-histórica das emoções humanas: a natureza sensorial e reflexa da reação emocional e a negação da sua relação com os estados intelectuais (Vigotsky, 2004, p.139). A teoria organicista não foi capaz de explicar como se concretizam as relações entre o afetivo e o intelectual, e, ao separar as emoções das outras funções no conjunto da consciência humana, o que ela fez foi colocar num mesmo patamar as emoções humanas e animais, desprezando aquilo que é especificamente humano.

Presente no território escolar, o argumento organicista da origem biológica das emoções humanas e de seu caráter a-histórico, tem servido para justificar um distanciamento entre o afetivo e o cognitivo nos processos de aprendizagem. Colocadas como rudimentos autônomos na estrutura psicológica, distantes da consciência, as emoções passam a se constituir em elementos "perturbadores", que interferem no "processamento cognitivo" dos conteúdos aprendidos.

Uma autora que se dedicou à análise do reducionismo biológico que tenta justificar as desigualdades sociais a partir da ciência biológica foi Agnes Heller. Em seu livro Sobre os Instintos, Heller (1983) faz referência ao tema da agressividade e dos instintos humanos criticando as teorias que identificam impulsos com instintos e, ao fazê-lo, acabam por relacionar instintos com afetos ou associam um afeto a cada instinto ou, ainda, derivam os afetos dos instintos (Heller, 1983, p.20). Com relação ao afeto, a teoria do instinto concorda que aquilo que não é baseado no discernimento, na aprendizagem ou na atividade intelectual é afetivo; o instinto "diminui a consciência", o mesmo acontecendo com o afeto; por este motivo, o instinto é afetivo. Em resumo, o pensamento de Heller se encaminha para mostrar que essa teoria considera o instinto como o motivo geral do comportamento ou da ação, enquanto ela, ao contrário, defende a tese segundo a qual o homem não é um ser guiado pelo instinto, e, embora reconheça a natureza como condição e limite da existência humana, ela nega que as motivações psíquicas sejam motivações biológicas (Heller, 1983).

Atualmente essa discussão sobre a origem biológica dos fenômenos psíquicos se materializa no organicismo presente no dia a dia da escola que busca, por meio das explicações reducionistas, situar no corpo físico das crianças as alterações e/ou déficits que justifiquem sua não aprendizagem. Em pesquisa sobre a medicalização dos processos de ensino e de aprendizagem, Collares \& Moysés (1996) ouviram opiniões de profissionais da educação e da saúde sobre as causas do fracasso escolar e constataram que, no conjunto analisado, todos referem problemas biológicos centrados na criança como causas do não aprender na escola, reforçando, principalmente, problemas neurológicos.

$\mathrm{Na}$ realidade educacional, esses dados traduzem o que atualmente se tem denominado de Transtorno de Déficit de Atenção com ou sem Hiperatividade (TDAH), dislexia e outros. Para explicitar a complexidade desse fenômeno, Eidt e Tuleski (2007) discutem o Transtorno do Déficit de Atenção e Hiperatividade (TDAH) e o aumento progressivo da medicalização de crianças em idade escolar diagnosticadas como agressivas, desatentas, hiperativas e impulsivas. O número expressivo de crianças que fazem uso de medicamentos tem crescido na mesma proporção dos estudos e 
pesquisas sobre esses distúrbios, mas esses estudos pouco contribuem para a definição do quadro clínico, para o diagnóstico e intervenção, pois ainda apoiam suas análises, exclusivamente, nas características individuais das crianças, considerando-as atípicas. As mesmas autoras (2007, 2010) destacam a necessidade de reinterpretar os mecanismos ideológicos que são utilizados no contexto da sociedade pós-moderna para justificar diferenças individuais a partir de análises biologicistas, fundadas sobre a aparente oposição entre corpo e mente.

Esse olhar dicotomizado, que elege o corpo como a instância produtora do problema na escola, é o mesmo que delega às emoções o papel de "interferências negativas" que, presentes, podem dar origem aos problemas de aprendizagem, numa visão reducionista dos elementos que perpassam a relação sujeito-objeto e, principalmente, do lugar ocupado pelos processos afetivos na constituição do conhecimento.

A crítica de Vigotski (2004) à maneira como a ciência psicológica vem explicando a unidade entre funções afetivas e cognitivas denota o caráter subjetivista, idealista e a-histórico desses processos, reforçando o assento naturalista presente na Psicologia desde o seu nascimento. Dessa forma, esse autor admite que o caminho para se encontrar uma verdadeira explicação teórica e metodológica da unidade afetivo-cognitiva na estrutura psicológica do sujeito não pode dispensar a análise da atividade humana - categoria constitutiva do psiquismo humano - na relação que esta mantém com a consciência.

\section{A relação sujeito-objeto e a}

\section{constituição do psiquismo humano}

Para ilustrar esses conceitos, recorremos à premissa fundamental do psiquismo como reflexo subjetivo do mundo objetivo, ou à tese materialista da existência dos fenômenos fora e independente da consciência humana de Espinosa (1632-1677) e Marx (1818-1883). Na filosofia de Espinosa o conceito de modo define-se por oposição ao de substância, daí dizermos que o modo possui uma dependência, que ele não existe em si e por si mesmo. Com efeito, caracterizar algo como um modo finito significa dizer que ele não dispõe de autossuficiência e que só pode ser compreendido a partir de sua relação com a substância e com os outros modos. A implicação direta dessa afirmação é tratar um modo - os corpos, as ideias, a mente, alma ou, em nossa linguagem contemporânea, a consciência - considerando seu processo de constituição e sua dependência existencial; ou seja, pensar o homem como um modo singular finito sugere a tarefa de refletir sobre a produção da natureza humana.

No interior dessa discussão, o aspecto que nos interessa é a possibilidade de aproximação entre a filosofia de Espinosa e a Psicologia Histórico-Cultural, fundamentalmente no que concerne à constituição da consciência humana e, em particular, ao espaço ocupado pelos processos afetivos e cognitivos na atividade do sujeito. Como uma das raízes do pensamento de Vigotski, evidenciando o papel da atividade no processo de constituição das funções psicológicas superiores do sujeito por meio das relações sociais e humanas, destaca-se esse fundamento da filosofia de Espinosa que, ao apresentar a alma como um modo,não pensou a sua existência como um a priori, mas como um vir a ser, confirmando a materialidade do seu pensamento.

Não cabe na filosofia espinosista um modo de pensamento que não seja derivado de uma afecção, de uma realidade que existe fora e independente do sujeito. Não há pensamento sem objeto. O pensamento é sempre de alguma coisa, e para Espinosa, a alma não é senão o pensamento ou a ideia do corpo e das coisas que afetam o corpo, sem nenhuma referência - repetimos - à ideia tradicional de uma alma substância, suporte das ideias (Teixeira, 2001, p. 122). Superar a relação dicotomizada entre corpo e alma pressupõe, primeiramente, entender que a alma é ideia das afecções corporais, dos movimentos, das ações e reações de seu corpo na relação com outros corpos, das mudanças e transformações sofridas pelo corpo sob a ação de causas externas.

O problema da vontade e da sua relação com o conhecimento é outro aspecto particularmente importante do pensamento de Espinosa,pois se constitui num atalho que conduz ao interior da sua epistemologia, sobretudo naquilo que esta oferece para compreendermos a origem dos afetos e sua relação com o conhecimento. Contrariando a tese cartesiana da vontade como livre-arbítrio (baseada na distinção entre intelecto e vontade e na ideia de que o conhecimento é um ato de vontade), Espinosa afirma que o conhecimento não é um produto da nossa vontade, visto que não existe uma faculdade da alma, assim como a alma também não existe como realidade substancial, capaz de armazenar a vontade. Esta só se concretiza afirmando ou negando algo de alguma coisa, ou seja, como conhecimento. Dando forma à relação entre o afetivo e o cognitivo na sua teoria, Espinosa afirma que se o conhecimento é a ideia em nós, esta ideia produz, necessariamente, um afeto, um desejo.

Quando o sujeito interpreta o desejo a partir de uma manifestação da essência humana, desligada e independente das condições concretas da sua existência, como um processo maior que o produziu, ele está destituindo o desejo da sua característica primeira, que é o conhecimento, uma vez que o desejo é determinado pelas afecções, pelas ideias das coisas ou por uma realidade externa ao sujeito, a partir do conhecimento. Agindo assim, o sujeito incorre no perigo de tratar o desejo como uma abstração. Em resumo, podemos dizer que a concepção do conhecimento em Espinosa é de início, uma proposição fundamentalmente anticartesiana, pois para ele não há outra forma de conhecer a si mesmo e a realidade senão por meio das ações que os outros corpos exercem sobre o sujeito. Uma implicação psicológica desse postulado é a dependência das condições objetivas de vida como elemento de complexificação da consciência - formulação histórico-cultural da materialidade dos processos psicológicos superiores.

Este percurso teórico, que nos remete à teoria do afeto, na forma como esta foi talhada por Espinosa no sé- 
culo XVII traz alguns elementos que nos apontam novas possibilidades para uma explicação da unidade entre afeto e cognição na constituição da consciência humana. Chegamos, finalmente, a Marx no século XIX, destacando que este foi o primeiro que, ao fazer uma análise teórico-crítica da natureza social do homem, ofereceu subsídios para pensarmos a subjetividade humana na sua determinação histórica e social, e neste território alicerçarmos novas considerações sobre a constituição materialista histórico-dialética dos processos cognitivos e afetivos na atividade do sujeito.

Um fundamento da concepção marxiana é a afirmação de que "O homem é diretamente um ser da natureza" (Marx, 1993, p. 249, grifo do autor), ou ainda, de que "(...) o homem é uma parte da natureza (...)” (Márkus, 1974a, p.8, tradução nossa). Isso significa pensá-lo como um ser objetivo que mantém com a natureza um intercâmbio a partir do qual produz e reproduz sua existência. Os pressupostos naturalistas e materialistas do pensamento de Marx apontam para o homem como um ser finito, limitado; ou seja, os objetos de suas necessidades - tanto as naturais como aquelas determinadas socialmente - existem fora dele. Afirma o filósofo:

\footnotetext{
Um ser que não tenha a sua natureza fora de si, não é nenhum ser natural, não participa do ser da natureza. Um ser, que não tenha objecto fora de si, não é nenhum ser objectivo. Um ser, que não seja ele próprio objecto para um terceiro ser, não tem existência para o respectivo objecto, quer dizer, não possui relação objectiva, o seu ser não é objectivo. Um ser não objectivo é um não-ser (Marx, 1993, p.250, grifo do autor).
}

Marx refere que a especificidade da atividade humana reside em que, ao transformar os objetos da natureza para o atendimento às suas necessidades, o homem, além de transformar a natureza exterior, transforma também e ao mesmo tempo sua natureza interior. O caminho teórico percorrido por Marx pressupõe que a essência da consciência se faz por meio do conhecimento. Se a realidade humanizada é condição objetiva para que o homem se aproprie da humanidade constituída pelo gênero humano, "(...) a condição subjetiva desse processo, em troca, reside no desenvolvimentoe no aperfeiçoamento da consciência humana" (Márkus, 1974b, p.58, grifo nosso), que faz dela, em todas as suas formas, "uma atividade decisivamente voltada para a apropriação da natureza" (idem, p.59). Se a consciência é, por definição, um sistema de conhecimentos, temos que considerar seu desenvolvimento ao longo de um processo, uma vez que ela não é "algo que já está dentro" do sujeito, mas é resultado de sua atividade no mundo objetivo. Quanto mais o ser humano amplia e elabora sua atividade, mais ele lida com os objetos e fenômenos da realidade como objeto alheio a ele, e neste processo, vai estruturando sua consciência, desenvolvendo-a a partir das condições materiais, sociais e culturais concretas em que vive.

A explicação, já anunciada por Espinosa, acerca do vínculo afecção-afeto que explicita a relação sujeito-objeto, visto que a ação do objeto sobre o sujeito (affectio) conduz, necessariamente, a uma ação do sujeito sobre esse mesmo objeto, constituindo o afeto (affectus), aponta para o primado do desenvolvimento da consciência na Psicologia Histórico-Cultural. Disso resulta que o processo de conhecimento não é uma atividade puramente subjetiva, dissociada da realidade concreta, mas nele - conhecimento - está posta a correlação entre o subjetivo e o objetivo. O pensamento é a expressão da unidade entre o sujeito e a realidade, porque dele resulta uma imagem subjetiva do mundo objetivo.

Segundo Kopnin (1978), a subjetividade do pensamento significa que este pertence ao homem como sujeito e, como tal, a representação que este mesmo sujeito faz dos objetos da realidade depende das suas condições concretas de vida. A contradição que sustenta a relação entre sujeito e objeto é pressuposto para o desenvolvimento da sua atividade no mundo e condição para o sujeito refletir cognitiva e afetivamente sobre suas próprias experiências. "As emoções e os sentimentos são uma das formas em que o mundo real se reflete no homem" (Smírnov, Leontiev, Rubstein, \& Tieplov, 1961, p. 355, tradução nossa, grifo do autor).

Destarte, a relação sujeito-objeto é a base sobre a qual se constitui o reflexo psíquico da realidade, daí a preocupação em apontar para o papel da educação escolar como mediadora na superação das formas primitivas de comportamento em direção às formas mais sofisticadas e complexas de apropriação dos objetos culturais. Tratar o reflexo psíquico como efeito da relação sujeito-objeto traz consigo a impossibilidade da imagem subjetiva de um dado objeto sem que este se coloque como objeto para um dado sujeito. É nessa trama que se dá o processo de apropriação-objetivação pelo sujeito - caracterizando o desenvolvimento do seu pensamento - e que se constituem as funções cognitivas e as funções afetivas (Gomes, 2008).

A distinção dessas funções no psiquismo permite concluir que as funções cognitivas constroem a imagem subjetiva do objeto em sua concretude e que as funções afetivas, igualmente, cumprem a representação da imagem do objeto, porém constroem a imagem da relação do sujeito com aquele objeto; portanto, o pensamento e os sentimentos são processos psicológicos desenvolvidos pelo homem na sua relação com o mundo.

A unidade afetivo-cognitiva é mediadora constante nas atividades realizadas pelo indivíduo ao longo de sua vida, portanto, tudo que a constitui é ao mesmo tempo, objeto do pensamento e fonte de sentimentos (Martins, 2007, p.129).

Abordar a unidade de afeto e cognição na constituição da consciência significa dizer que o sujeito vivencia, percebe e interpreta as ações dos outros corpos, fenômenos e ideias sobre ele, determinando a possibilidade do conhecimento. A vivência ou aquilo que o sujeito experiencia, o que atravessa sua existência objetiva - transformando significados sociais em sentidos pessoais - constitui sua atividade. É por meio dessa atividade que o sujeito responde às solicitações do meio circundante, e é também por meio dela que o sentido pessoal se realiza; o fato é que de uma dada atividade sempre advém um sentido, que é conteúdo da consciência. 
Entendemos que, por ser o motor da atividade - o que a impulsiona, dirige e orienta -, o motivo é síntese do objetivo e do subjetivo. Pensar na motivação é aceitar que existe uma relação entre a necessidade - como estado carencial (subjetivo) - e a identificação do objeto (objetivo), e que mediando tal processo está um mecanismo de descoberta que se faz por meio da atividade do sujeito.

Essa necessidade como força interior pode realizar-se somente na atividade. Pensá-la como algo intrínseco, inerente ao sujeito, é incorrer no risco de um pensamento subjetivista e idealista. Se a necessidade se efetiva em motivo por meio do conhecimento, o modo como esse objeto é percebido, concebido e representado pelo sujeito, ou seja, o seu conhecimento, dependerá de como acontecem as mediações entre sujeito e realidade concreta, uma vez que esses mesmos objetos vão se modificando e se transformando, e ao fazê-lo, transformam os motivos. O mesmo acontece com relação às emoções e/ou afetos e sentimentos: estes também são engendrados a partir de uma correlação entre a atividade objetivada do sujeito e seus motivos (Leontiev, 1978).

Aquilo que afeta a atividade, movimentando-a ou não, o faz porque se relaciona com os motivos construídos na história de vida de cada sujeito em particular, a partir das mediações estabelecidas com a realidade. As emoções não são o reflexo mesmo dos objetos (Smírnov e cols., 1961), mas o reflexo da relação que existe entre aquele objeto, as necessidades e os motivos do sujeito, por isso são vivências e por isso Vigotski não deixou de contemplar o afetivo e o cognitivo como uma unidade constante nesse processo, mediando a relação atividade-consciência na constituição do psiquismo humano.

\section{Considerações finais}

O destaque dado ao afetivo como um problema da educação escolar marcou nossa preocupação em dialogar tanto com a Psicologia quanto com a Educação, buscando romper com algumas dicotomias que permanecem enraizadas na escola, entre as quais se destaca a cisão entre o afetivo e o cognitivo. Essa disposição da Psicologia, que alimenta a perspectiva da naturalização dos processos psicológicos, traz consequências diretas para o campo da educação escolar, pois condiciona uma visão de aprendizagem e de desenvolvimento. Ao tratar as emoções como "elementos perturbadores", "empecilhos" nos processos de conhecimento, a escola afirma sua posição de colocar-se a serviço apenas do desenvolvimento cognitivo, ou postula o desenvolvimento afetivo como uma organização interna do sujeito, um dado que se desenvolve apartado das demais funções psicológicas.

Contrariando esse ideário hegemônico, que encerra o afetivo no plano intrapsíquico do sujeito como algo inerente à sua personalidade, admitíamos a hipótese de que era possível compreender a constituição dos processos afetivos e dos cognitivos tomando por base a atividade do sujeito; e, uma vez que essa atividade se enraíza nas suas condições concretas de vida, deveríamos pontuar o caráter histórico e cultural dessa constituição. Perguntávamos se era possível explicar a constituição e a participação dos processos afetivos na atividade do sujeito apontando para a escola um lugar e uma função na superação da dicotomia entre afeto e cognição, com vistas ao desenvolvimento omnilateral da criança.

A partir desse recorte teórico-conceitual, esperamos ter podido demonstrar a tese segundo a qual Vigotski buscou explicar e compreender a constituição dos processos cognitivos e afetivos por meio da atividade do sujeito intermediada pelos instrumentos e signos que, ao serem apropriados, passam a fazer parte da consciência, conformando a particularidade psíquica de cada indivíduo humano. Eis porque encontramos no sentido pessoal a unidade de afeto e cognição, pois, como síntese da atividade de apropriação-objetivação, é só por meio dele que o significado social adquire existência subjetiva. Assim, compreender afeto e cognição sem reconstruir a história de apropriações e objetivações que o sujeito faz a partir do conjunto de conhecimentos socialmente construídos e entender como estes potencializam ou não o sujeito para a ação levam a sucumbir ao subjetivismo,que é marca da psicologia tradicional burguesa.

Sendo assim, falar dos afetos, da vontade, de interesses ou motivação, significa dizer que eles acontecem em relação ao grupo a que o sujeito pertence e requer explicitar de que lugar o sujeito fala, qual é seu espaço social, seu acesso e domínio dos conhecimentos historicamente acumulados. Dizer que o pensamento e os sentimentos são processos psicológicos desenvolvidos pelo sujeito na sua relação com o mundo e que, por isso mesmo, as funções psicológicas superiores são exigidas por uma dada forma de relação desse sujeito com os objetos do conhecimento, conclama os profissionais da Psicologia e da Educação - que permanecem simplificando problemas e demandas muito complexas que nos chegam a partir do contexto educacional, entre elas a questão dos "problemas emocionais",tão proclamados no campo da (não) aprendizagem escolar - a pensar sobre como se apresentam e se estruturam as atividades pedagógicas, como a escola pensa e executa a organização da atividade da criança em suas diferentes etapas de escolarização, ou seja, como aqueles que atuam no interior da escola julgam sua participação na constituição dos processos afetivos e cognitivos.

\section{Referências}

Bissoli, M. F. (2005). Educação e desenvolvimento da personalidade da criança:Contribuições da Teoria Histórico-Cultural. Tese de Doutorado, Universidade Estadual Paulista, Marília-SP.

Chauí, M. (2005). Espinosa:uma filosofia da liberdade. São Paulo: Moderna.

Collares, C .A. L., \& Moysés, M. A. A. (1996). Preconceitos no cotidiano escolar: ensino e medicalização. São Paulo: Cortez. 
Eidt, N. M., \& Tuleski, S. C. (2007). Discutindo a medicalização brutal em uma sociedade hiperativa. Em M. E. M. Meira \& M. G. D. Facci (Orgs.), Psicologia Histórico-Cultural: contribuições para o encontro entre a subjetividade e a educação (pp. 221-248). São Paulo: Casa do Psicólogo.

Eidt, N. M., \& Tuleski, S. C. (2010). Transtorno de déficit de atenção/ hiperatividade e Psicologia Histórico-Cultural. Cadernos de Pesquisa, 40(139), 121-146.

Espinosa, B. (2004). Ética demonstrada à maneira dos geômetras. São Paulo: Nova Cultural.

Gomes, C. A. V. (2008). O afetivo para a psicologia Histórico-Cultural: considerações sobre o papel da educação escolar. Tese de doutorado, Universidade Estadual Paulista, Marília-SP.

Heller, A. (1983). Sobre os instintos. Lisboa: Editorial Presença/ Martins Fontes.

Kopnin, P. V. (1978). A dialética como lógica e teoria do conhecimento. Rio de Janeiro: Civilização Brasileira.

Leontiev, A. (1978). Actividad, conciencia y personalidad. Buenos Aires: Ediciones Ciências del Hombre.

Márkus, G. (1974a). Marxismo e antropologia. Barcelona: Grijalbo.

Márkus, G. (1974b). A teoria do conhecimento no jovem Marx. Rio de Janeiro: Paz e Terra.

Martins, L. M. (2006). A brincadeira de papéis sociais e a formação da personalidade. Em N. Duarte \& A. Arce (Orgs.), Brincadeira de papéis sociais na educação infantil:as contribuições de Vigotski, Leontiev e Elkonin (pp. 27-50). São Paulo: Xamã.

Martins, L. M. (2007). Algumas reflexões sobre o desenvolvimento omnilateral dos educandos. Em M. E. M. Meira \& M. G. D. Facci (Orgs.), Psicologia Histórico-Cultural: contribuições para o encontro entre a subjetividade e a educação (pp. 117-134). São Paulo: Casa do Psicólogo.

Marx, K. (1993). Manuscritos econômico-filosóficos. Lisboa: Ed. 70.

Meira, M. E. M., \& Antunes, M. A. (2003). Psicologia escolar: teorias críticas. São Paulo: Casa do Psicólogo.
Patto, M. H. S. (1999). A produção do fracasso escolar:histórias de submissão e rebeldia. São Paulo: Casa do Psicólogo.

Patto, M. H. S. (2000). Mutações do cativeiro: escritos de psicologia e política. São Paulo: Hacker editores / Edusp.

Smírnov, A. A., Leontiev, A. N., Rubinstein, S. L., \& Tieplov, B. M. (1961). Psicologia. Havana: Imprenta Nacional de Cuba.

Souza, M. P. R. (1997). A queixa escolar e o predomínio de uma visão de mundo. Em A. M. Machado (Org.), Psicologia escolar: em busca de novos rumos (pp. 17-33). São Paulo: Casa do Psicólogo.

Souza, M. P. R. (2007). Prontuários revelando os bastidores: do atendimento psicológico à queixa escolar. Em B. P. Souza (Org.) Orientação à queixa escolar (pp. 27-58). São Paulo: Casa do Psicólogo.

Teixeira, L. (2001). A doutrina dos modos de percepção e o conceito de abstração na filosofia de Espinosa. São Paulo: Editora UNESP.

Vigotski, L. S. (1972). Psicología del Arte. Barcelona: Barral Editores.

Vigotskii, L. S. (1987). Imaginacion y el arte en la infância. México: Hispânicas.

Vygotski, L. S. (1991). Obras Escogidas I. Madrid: Visor.

Vygotski, L. S. (1993). Obras Escogidas II. Madrid: Visor.

Vygotski, L. S. (1995). Obras Escogidas III. Madrid: Visor.

Vygotski, L. S. (1996). Obras Escogidas IV. Madrid: Visor.

Vygotsky, L. S., \& Luria, A. R. (1996). Estudos sobre a história do comportamento: símios, homem primitivo e criança. Porto Alegre: Artes Médicas.

Vigotsky, L. S. (2000). A construção do pensamento e da linguagem. São Paulo: Martins Fontes.

Vigotski, L. S. (2003). O desenvolvimento psicológico na infância. São Paulo: Martins Fontes.

Vigotsky, L. S. (2004). Teoria de las emociones (Estúdio histórico psicológico). Madrid: Ediciones Akal. 


\section{Sobre a autora}

Cláudia Aparecida Valderramas Gomes (cabegomes@uol.com.br e claugomes@assis.unesp.br)

Professora Assistente Doutora do Departamento de Psicologia Evolutiva, Social e Escolar da Universidade Estadual Paulista - UNESP Campus de Assis-SP.

Trabalho derivado de Tese de Doutorado intitulada O afetivo para a Psicologia Histórico-Cultural: considerações sobre o papel da educação escolarque contou com o auxílio financeiro da CAPES e anteriormente apresentado no X Congresso Nacional de Psicologia Escolar e Educacional - CONPE/2011. 